\title{
Diphtheria IgG Antibody Measurement
}

National Cancer Institute

\section{Source}

National Cancer Institute. Diphtheria IgG Antibody Measurement. NCI Thesaurus. Code C103388.

The determination of the amount of the Diphtheria IgG antibodies in a sample. 